\title{
Reforma da previdência e regime complementar*
}

\author{
Pension reform and fully funded \\ complimentary regime
}

\author{
LENA LAVINAS** \\ ELIANE DE ARAÚJO***
}

RESUMO: Este artigo interroga a relação entre o sistema público de aposentadorias e pensões no Brasil e o regime complementar de capitalização (ou de contribuição definida), ante mais uma investida de reforma contra o seguro social. Após caracterizar brevemente o perfil do sistema público e a evolução recente das aposentadorias fully-funded, discute os pressupostos de que este regime seria mais benéfico à elevação da poupança privada e, portanto, do investimento, dimensões sempre problemáticas da dinâmica do desenvolvimento no Brasil. Conclui que a expansão da previdência complementar privada não contribui nem para o aumento do investimento, nem para a ampliação do mercado de capitais, tendendo, ao contrário, a estimular a concentração de renda, já alarmante no país.

PALAVRAS-CHAVE: Previdência; seguro social; regime de capitalização complementar; Brasil.

ABSTRACT: This article examines how pay as you go (defined benefit) public pension system relates to a fully funded complimentary regime (or defined contribution pension), in the context of a renewed attempt to reform public retirement benefits in Brazil. After featuring the main characteristics of the public pension system and how the fully funded private regime has evolved as of late, this paper questions the idea that the latter would be more beneficial to the increase of private savings and, as a result, of investment, aspects that are crucial for the development of Brazil. The findings suggest that the fully funded private regime, rather than incentivizing investment growth and the stock market, tends to reinforce income concentration, which is by all standards already alarming in Brazil.

KEYWORDS: PAYG system; social insurance; fully funded complimentary regime; Brazil. JEL Classification: H55; H58; J11; J21; J24.

\footnotetext{
* Agradecemos a Ana Carolina Cordilha e Norberto Montani o valioso apoio na coleta dos dados.

** Fellow do Wissenschaftskolleg zu Berlin 2016-2017, professora titular do Instituto de Economia da UFRJ e bolsista nível 1 do CNPq.

*** Professora da Universidade Estadual de Maringá e bolsista produtividade em pesquisa do CNPq.
} 


\section{INTRODUÇÃO}

Desde sua reformulação em 1988, o seguro social vem passando, no Brasil, por uma série de mudanças paramétricas que parecem colocar em xeque sua sustentabilidade no longo prazo, incentivando o desenvolvimento da previdência privada em detrimento do regime de repartição, ou pay as you go (PAYG).

Ao final de 2016, nova proposta de reforma foi encaminhada ao Congresso, desta feita não apenas ajustando este ou aquele parâmetro, mas propondo alterações que fragilizam o desenho e a cobertura originais da previdência pública, tal como desenhada quando da repactuação do contrato social.

A reforma da previdência - ou a PEC 287 - vale-se de duas linhas de argumentação para justificar mudanças de caráter abrangente e estrutural, modificando um modelo previdenciário que se consolidou na fase recente de crescimento (2004-2014). De um lado, levanta a ameaça de que o célere envelhecimento da população brasileira leve ao colapso do sistema público de aposentadorias nas próximas décadas. Estimativas elaboradas pelo governo sinalizam que a participação da população com mais de 60 anos no Brasil passaria de 12,59\% do total da população em 2015, para $35,15 \%$ em $2060^{1}$.

De outro, retoma o argumento de que há que se elevar a taxa de poupança das famílias, sabidamente baixa no país, e, assim, contribuir para o aumento da taxa de investimento, igualmente insuficiente. Para incentivar esse movimento, não apenas se altera o sistema público, mas ao fazê-lo se estimula o fortalecimento dos regimes de capitalização que têm registrado um desenvolvimento bastante significativo na última década.

Ora, um documento ${ }^{2}$ recém-elaborado por um grupo de especialistas vem a público contestar os modelos do governo, no que se refere ao ritmo de envelhecimento da população. Faz isso de duas maneiras: aponta que o grau de transparência dos métodos utilizados na projeção dos resultados previdenciários é limitado (Puty et al., 2017), e sinaliza que outras variáveis importantes para o financiamento do sistema previdenciário precisam ser levadas em consideração para sugerir medidas mais amplas que possam melhorar os resultados financeiros desse sistema (Gentil et al., 2017); e, finalmente, alerta para o fato de que as previsões estatísticas jamais são isentas de erros, motivo pelo qual o método de projeção utilizado pelo governo deveria calcular e delimitar os erros para as projeções sobre o comportamento do sistemas previdenciários (Carvalho et al., 2017).

Mas o que dizer da outra linha de argumentação que aposta na expansão da previdência privada para resolver problemas de natureza macroeconômica pendentes e reiteradamente apontados como um dos grandes obstáculos ao crescimento sustentado da economia brasileira? A solução passa pela reforma da previdência?

Neste artigo, vamos analisar como a dinâmica do sistema público de previdên-

\footnotetext{
${ }^{1}$ Puty et al. (2017).

${ }^{2}$ Puty e Gentil (2017).
} 
cia impacta na progressão dos regimes de previdência complementar e avançar algumas hipóteses sobre a natureza e consequências da nova onda de reformas previdenciárias em curso.

Após esta introdução, aprofundamos, na segunda seção, a evolução recente do regime de repartição no Brasil, a cobertura que oferece e sinalizamos as sucessivas reformulações no seu desenho. Na terceira seção, sintetizamos que relações existem entre o sistema de repartição público e os fundos de capitalização, evidenciando os equívocos de incentivar as contas individuais a partir de uma reforma míope do Regime Geral da Previdência Social (RGPS). A quarta seção examina como a dinâmica do sistema público impactou na progressão dos regimes de previdência complementar no Brasil e avança algumas hipóteses sobre a natureza e consequências da nova onda de reformas previdenciárias em curso. A conclusão fecha o artigo chamando a atenção para a importância de preservar e fortalecer o sistema público de repartição operando transformações no sentido de elevar o teto de contribuição, para que a previdência social se mantenha como um dos mecanismos mais efetivos de redistribuição, para além de suas outras funções precípuas.

\section{O QUE MUDOU NO SISTEMA PREVIDENCIÁRIO BRASILEIRO DESDE 1988}

As aposentadorias foram alvo de inovações marcantes na Constituição de 1988, com a instituição do piso previdenciário vinculado ao salário mínimo nacional e a extensão do direito a um benefício na velhice aos pequenos produtores rurais, independentemente de contribuição compulsória prévia nos moldes e prazos exigidos aos demais beneficiários. Em conformidade aos contribuintes do sistema de repartição simples, os rurais passam a receber um salário mínimo ao se aposentar. No caso das mulheres, a idade mínima é 55 anos e, no caso dos homens, 60 anos. Em 2015, o número de aposentados especiais, como são denominados, alcança 8,5 milhões de pessoas.

Em paralelo, a Constituição consagrou o seguro social em regime de repartição simples na esfera pública e instituiu dois sistemas: o Regime Geral da Previdência Social, que cobre, com um leque diverso de benefícios, a população em idade ativa, seja ela ocupada no setor privado (compulsório), rural, trabalhadores autônomos que optam pela contribuição voluntária, donas de casa, estudantes e quem mais quiser aderir mediante contribuição; e o Regime Próprio da Previdência Social (RPPS) que atende, em separado, ao funcionalismo federal, militares, ao legislativo e judiciário e ainda a uma pequena parcela de servidores ocupados em nível subnacional. E criou a previdência complementar privada, fechada e aberta, em regime de capitalização. A previdência complementar aberta não é compulsória, mas incentivada através de deduções tributárias no imposto de renda de pessoa física. Já a fechada, no âmbito de determinadas empresas públicas, é compulsória.

As regras do seguro social tendem a convergir. Entretanto, o sistema previdenciário brasileiro mantém ainda um viés bastante segmentado. 
Incluindo a previdência dos rurais, o RGPS paga mensalmente cerca de 26 milhões de aposentadorias e pensões, sendo $62 \%$ delas no valor de um salário mínimo ${ }^{3}$. Já o RPPS distribui 3,5 milhões de benefícios ${ }^{4}$ (Ministério da Previdência, 2015). As despesas do RGPS e do RPPS equivalem, respectivamente, a 7,4\% do PIB e 2,1\% do PIB em 2015.

Constata-se, assim, que o Brasil resistiu à onda de privatização do seu sistema previdenciário nos anos 1980 - na contramão, portanto, do que se passava em bom número de países latino-americanos.

A literatura especializada enfatiza que as aposentadorias não têm como único objetivo a redução da pobreza, mas também suavização do consumo, redistribuição e oferta de um seguro contra determinados riscos (Barr, 2004). Na próxima seção vamos nos debruçar sobre a evolução recente do sistema de aposentadorias no Brasil, para entender se ele vem sendo amputado de alguma dessas dimensões, intrínsecas à sua finalidade (Barr, 2004; Barr e Diamond, 2008). Para tal, analisamos seu desenho e as alterações sofridas a partir de 1988.

\section{PREVIDÊNCIA: RESTRINGINDO O PÚBLICO PARA ESTIMULAR O PRIVADO}

Como sinalizado acima, o Brasil dispõe de dois regimes previdenciários públicos, além de um regime facultativo de capitalização complementar.

O Regime Geral da Previdência Social é contributivo e compulsório para os empregados formais do setor privado. Alcança também segurados voluntários, com status ocupacionais diversos. A alíquota de contribuição é de $20 \%$ sobre salário ou sobre qualquer valor de contribuição que se situe entre o piso previdenciário (salário mínimo vigente) e o teto de contribuição, fixado, em 2016, em R \$ 5.189,00 mensais. Essa alíquota de $20 \%$ é compartilhada entre trabalhadores e empregadores. A parcela que incumbe aos trabalhadores é progressiva, variando de $8 \%$ a $11 \%$, sendo o restante a parte patronal. Os contribuintes não sujeitos à relação salarial pagam alíquota integral de $20 \%$, exceção feita no caso dos Microempreendedores Individuais ou $\mathrm{MEI}^{5}$, cuja alíquota cai para $5 \%$ do salário mínimo (como medida

\footnotetext{
3 Salário mínimo em 2015 correspondia a R \$ 880,00. O valor médio das aposentadorias do RGPS em dezembro de 2015 é de pouco mais de R \$1.000,00, portanto, apenas ligeiramente acima do salário mínimo.

${ }^{4} \mathrm{O}$ valor médio das aposentadorias do Executivo federal corresponde a $\mathrm{R} \$ 7.400,00$ mensais. No caso dos militares, esse valor sobe para $\mathrm{R} \$ 9.400,00 \mathrm{e}$, em se tratando do corpo legislativo, bate em R\$ 28.550,00 (valores constantes em dezembro de 2015, Ministério da Previdência, 2015).

${ }^{5}$ Criada em 2008, a figura do Microempreendedor Individual (MEI) reúne cerca de 250 ocupações geralmente exercidas por self-employed. É MEI todo pequeno empreendedor individual, exercendo atividade econômica sem sócios e contratando não mais que um empregado, e cuja receita bruta, no ano-calendário anterior, não tenha ultrapassado $\mathrm{R} \$ 60.000,00$. Ao se aposentar por idade (condição imposta), o MEI vai receber o piso previdenciário estipulado constitucionalmente de um salário mínimo.
} 
de estímulo), e dos pequenos agricultores familiares, que sofrem incidência de 2,1\% sobre o valor da receita bruta da comercialização da sua produção.

Pelo lado dos benefícios, o seguro social oferece de aposentadorias e pensões até salário-maternidade ${ }^{6}$, seguro-desemprego, salário-família ${ }^{7}$, auxílio-doença, auxílio-acidente, auxílio-reclusão ${ }^{8}$, entre outros. As regras variam de acordo com o status do segurado, mas caminharam nos últimos anos na direção de uma crescente uniformidade, inclusive entre o RGPS e o RPPS.

A regra atual estabelece que aposentadoria pode ser requisitada pelos homens quando somarem, entre tempo de contribuição obrigatória ${ }^{9}$ e idade, 95 anos. No caso das mulheres, esse total cai para 85 anos. Essa regra, denominada progressiva, foi aprovada em $2015^{10}$, como alternativa à supressão, pelo Congresso, do fator previdenciário ${ }^{11}$. Este foi instituído em 1999, na segunda gestão FHC. Ao considerar a esperança de vida média, incorporando-a à contagem dos anos de contribuição e idade, o fator tinha por finalidade desincentivar aposentadorias precoces, aplicando um redutor no valor do benefício. Como a esperança de vida aumenta a cada ano, muitos trabalhadores passaram a adiar seu pedido de aposentadoria, de modo a receber a integralidade de seu benefício, em lugar de uma fração. Essa fórmula 85-95 é transitória e deveria, até 2027, alcançar 90-100 anos, para mulheres e homens, respectivamente, eliminando o diferencial de gênero de cinco anos, favorável às mulheres.

A adoção do fator previdenciário foi uma das reformas paramétricas mais importantes desde a reformatação do seguro social em 1988 e a consequente criação da Seguridade. Não foi, porém, a única. Ainda no governo FHC, teve lugar a primeira reforma da Previdência (1998) pós- Constituição. No que se refere ao RGPS, ela substituiu a opção "tempo de serviço" 12 pelo "tempo de

Isso explica a forte adesão a essa categoria, levando a que o número de contribuintes passasse de 44 mil pessoas em 2008 para 5,7 milhões em 2015.

${ }^{6}$ Seis meses pela lei, para as assalariadas dos setores privado e público.

${ }^{7}$ Para trabalhadores formais com remuneração de até 1,5 salário mínimo mensal.

${ }^{8} \mathrm{O}$ auxílio-reclusão destina-se aos dependentes de trabalhadores presos em regime semiaberto ou fechado, que estejam contribuindo regularmente para o seguro social, no momento de sua prisão.

${ }^{9}$ Segundo a lei, o tempo mínimo de contribuição obrigatória para homens é de 35 anos, e de 30 anos para as mulheres. E são necessários ao menos 180 meses efetivamente trabalhados para efeito de carência. Entretanto, quem tiver mais anos de contribuição, pode combinar esse diferencial com idade abaixo do mais frequente ( 55 anos para mulheres e 60 para os homens), e vice-versa.

${ }^{10}$ Essa regra não substitui as duas fórmulas pretéritas de obtenção de uma aposentadoria: a) a aposentadoria "por idade"; b) a aposentadoria "por tempo de contribuição" para os que tiverem direito adquirido.

${ }^{11}$ A finalidade do fator previdenciário era reduzir o valor dos benefícios previdenciários no momento de sua concessão, de maneira inversamente proporcional à idade de aposentadoria do segurado. Quanto menor a idade de aposentadoria, maior o redutor e, consequentemente, menor o valor do benefício.

${ }^{12} \mathrm{O}$ Brasil dispunha de um regime antigo que permitia a concessão de aposentadorias a quem pudesse comprovar 30 anos de serviço, embora sem contribuição regular. Foi suprimido. 
contribuição"; eliminou a aposentadoria proporcional; desvinculou os benefícios de valor superior ao salário mínimo da regra de indexação deste; e estabeleceu um teto nominal para os benefícios previdenciários, rompendo com a regra vigente do teto de 10 salários mínimos. Esta última medida foi estratégica para impulsionar a adesão ao regime de capitalização aberto, ainda incipiente e pouco demandado pela população.

Tendo sido estabelecido um teto de benefício relativamente baixo ${ }^{13}$, aqueles trabalhadores com rendimentos superiores contribuem para o sistema público apenas até o teto. $\mathrm{Na}$ busca por assegurar uma renda de substituição mais elevada, compatível com o salário da ativa, voltam-se para o setor financeiro, contribuindo para a previdência complementar. A consequência mais imediata foi comprometer o princípio de solidariedade intergeracional, característico do regime de repartição, deslocando para o mercado de seguros privados receita não desprezível da franja mais rica da população, que deveria estar sendo canalizada para o sistema público, de modo a fomentar a redistribuição e fortalecer o equilíbrio financeiro do sistema.

A gestão FHC também mexeu com o regime previdenciário dos servidores públicos, estendendo ao RPPS mudanças oriundas da reforma do RGPS: incorporação do conceito de "tempo de contribuição" em substituição ao de "tempo de serviço"; extinção da aposentadoria proporcional, conforme regras de transição idênticas às do RGPS; e a introdução do limite de idade para a aposentadoria do servidor público, aos 60 anos, regra não extensiva, à época, ao RGPS.

A reforma mais impactante do Regime Próprio da Previdência Social (RPPS) teve lugar na primeira administração de Luiz Inácio Lula da Silva, logo no seu primeiro ano de governo. Em 2003, foi aprovado o fim da aposentadoria integral para o funcionalismo ${ }^{14}$, além de tornar compulsória ${ }^{15}$ a contribuição dos aposen$\operatorname{tados}^{16}$. A taxação dos inativos no RPPS passou a vigorar retroativamente. Com isso, os servidores públicos aposentados, cujos proventos ultrapassem o teto dos benefícios, passaram a contribuir com $11 \%$ do valor de suas aposentadorias ou pensões.

Porém, o alvo principal da reforma do RPPS foi a uniformização do teto entre os dois regimes públicos. Pela nova regra, o servidor que ganhar acima do teto do RGPS (R \$ 5.189,00 mensais em 2016) e optar pelo benefício previdenciário com-

\footnotetext{
${ }^{13}$ Pouco mais de duas vezes o rendimento médio da população.

${ }^{14}$ Emenda Constitucional no 41/2003. Os funcionários públicos já aposentados ou que contavam com o chamado direito adquirido (que reúnem condições para pedir aposentadoria, mas preferem continuar trabalhando) tiveram e têm assegurada na reforma a integralidade de seus benefícios.

${ }^{15}$ Os aposentados do RGPS, por força do que estabelece o art. 195, II da CF/88, não precisam contribuir sobre suas aposentadorias e pensões, exceto se voltarem a trabalhar.

${ }^{16}$ Está obrigado a contribuir com $11 \%$ do valor dos proventos de sua aposentadoria ou pensão todo aquele cujo benefício ultrapasse o teto estabelecido para os benefícios do RGPS, ou seja, R \$ 5.189,00 (\$ 1,404.6) em 2016.
} 
plementar poderá vincular-se ao fundo de pensão fechado do funcionalismo. Essa foi, sem dúvida, a modificação mais substantiva da reforma do RPPS, pois compromete o regime de repartição simples, transformando o seguro social dos servidores públicos em regime misto, tornando incontornável sua adesão a um fundo de capitalização. O percentual dessa contribuição deverá ser definido pelo servidor (entre as opções de $7,5 \%, 8 \%$ ou $8,5 \%$ ), com a contrapartida paritária do governo ${ }^{17}$. O novo regime de capitalização denominado Funpresp-Exe, entretanto, só veio a ser regulamentado no primeiro mandato da presidente Dilma Rousseff ${ }^{18}$, quando entrou em vigor, estando vinculado ao Ministério do Planejamento (fora da alçada do Ministério da Previdência Social).

Assim, a previdência do setor público foi radicalmente transformada, exceto a dos militares, que se mantém inalterada, escapando a qualquer ajuste, embora represente $45 \%$ do déficit estimado do RPPS ${ }^{19}$.

Com relação à aposentadoria complementar, dois instrumentos foram criados ainda nos anos 1990: o Plano Gerador de Benefício Livre (PGBL) e o Vida Gerador de Benefício Livre (VGBL), ambos disponíveis junto a instituições financeiras privadas. O primeiro tem caráter previdenciário: destina-se à formação de uma renda de substituição no longo prazo. Já o segundo se assemelha a um seguro juntando, em um mesmo contrato, coberturas securitárias de vida e acidentes pessoais ${ }^{20}$.

O Gráfico 1 coteja a evolução recente dos fundos de previdência complementar abertos e fechados ${ }^{21}$. No caso das contas individuais abertas, sua expansão entre 2002 e 2015 superou a taxa de $2.000 \%$, além de sinalizar um crescimento relativamente constante e indiferente ao contexto macroeconômico. O ritmo se acentua notadamente a partir de 2008. Já os fundos fechados viram seus ativos aumentarem em $76 \%$ no mesmo período, sendo que a partir de 2012 registram tendência declinante, voltando a patamares de 2007. Embora de magnitude muito diversa, os valores plotados no Gráfico 1 traduzem o grande interesse que despertam as contas individuais de capitalização nos anos 2000, destacando a crescente adesão da população aos fundos de capitalização abertos.

\footnotetext{
${ }^{17}$ Os servidores que recebem remuneração inferior ao teto do RGPS também podem contribuir para a Funpresp-Exe, mas sem direito à contrapartida da União.

${ }^{18}$ A Lei n ${ }^{\circ}$ 12.618, de 30 de abril de 2012, que institui o Regime de Previdência Complementar para os Servidores Públicos Federais, fixa o limite máximo para a concessão de aposentadorias e pensões igual ao do teto do RGPS. Esta também autorizou a criação de três Entidades Fechadas de Previdência Complementar - nome oficial dos chamados fundos de pensão - para administrar o plano de benefício dos servidores dos três poderes: Executivo, Judiciário e Legislativo.

19 Cf. <http://oglobo.globo.com/economia/militares-respondem-por-quase-metade-do-deficit-daprevidencia-20470974>.

${ }^{20}$ A grande diferença entre essas duas modalidades de aposentadorias fully-funded reside no tratamento tributário de cada plano. O PGBL permite abater da base de cálculo do IRPF os aportes realizados anualmente ao plano até um limite máximo de $12 \%$ da renda bruta tributável do investidor.

${ }^{21}$ A metodologia usada nos dois casos difere. Empregou-se a categoria "patrimônio líquido" no caso dos fundos de capitalização abertos e "ativos totais" no caso dos fundos fechados.
} 
Gráfico 1: Brasil, Patrimônio Líquido dos Fundos de Previdência

Abertos e Ativos Totais dos Fundos de Previdência

Fechados, 2002 a 2015 (bilhões de Reais em 2015)

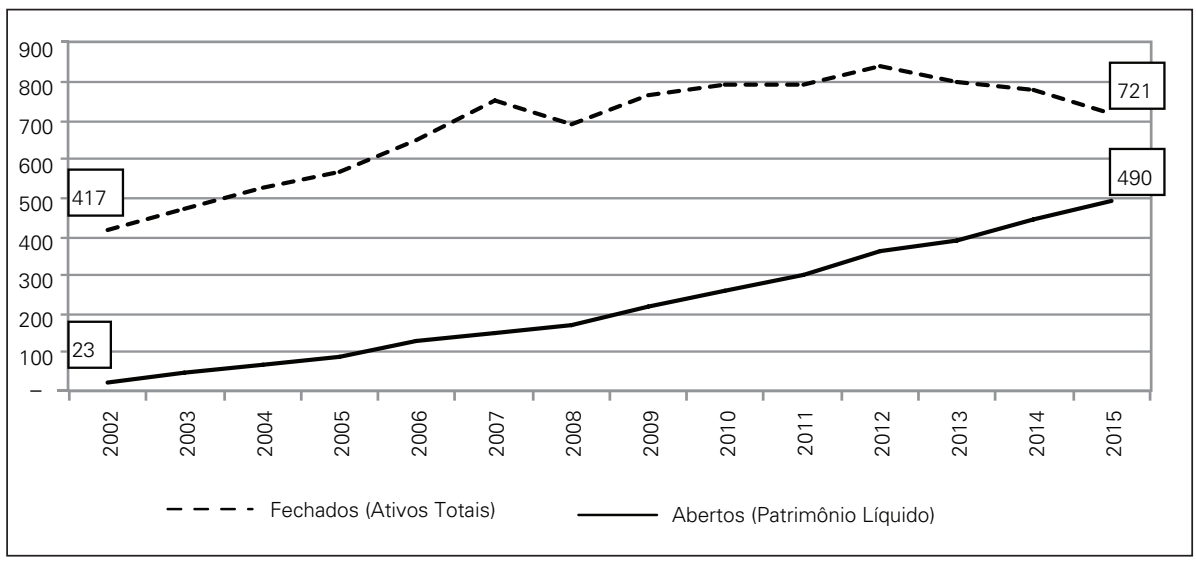

Fonte: ANBIMA e PREVIC. Valores ajustados pela inflação segundo o índice IPCA para dezembro de 2015.

Segundo vertentes da teoria econômica, a razão que justificaria privilegiar e fortalecer os sistemas de capitalização, através de um conjunto de incentivos e limites ao sistema de repartição, ou literalmente fechar os sistemas públicos, tornando os fundos privados exclusivos e compulsórios, como ocorreu no Chile nos anos 1980-90, seria a contribuição decisiva dos fundos fully funded ao fomento ao crescimento econômico, mediante o estímulo à poupança individual no longo prazo. Esta, através das contas individuais, seria absorvida no investimento produtivo doméstico, estimulando a inovação e o aumento da produtividade, levando ao crescimento do produto. Sem falar no estímulo à consolidação do mercado de capitais, notadamente nos países em desenvolvimento, onde cabe prioritariamente ao Estado o financiamento da atividade privada. Esses desdobramentos nem de longe são automáticos, como sublinha Barr (2004).

Mesa-Lago (2002) já havia contestado tais correlações, afirmando não haver evidências empíricas robustas de que o desenvolvimento de sistemas de capitalização impacta positivamente a poupança nacional. No âmbito do Banco Mundial, um grupo de avaliação independente (IEG, 2006) que analisou as propostas da agência em favor do fortalecimento do regime de capitalização chega às mesmas conclusões e afirma ainda que tampouco se verifica correlação entre contas individuais em fundos abertos e desenvolvimento do mercado de capitais ${ }^{22}$.

O mais recente trabalho que revisita essas teorias foi realizado por Altiparmakov e Nedeljkovic (2016). Os autores buscaram captar os efeitos da privatização das aposentadorias e pensões em duas regiões onde isso ocorreu de forma

\footnotetext{
22 "Also, the secondary objectives of funded pillars-to increase savings, develop capital markets, and improve labor flexibility-remain largely unrealized”(2006:x).
} 
relativamente generalizada e profunda, América Latina e Leste Europeu, servindo-se de uma base de dados ampla, cobrindo um grande número de países. Seus resultados econométricos indicam, com grande segurança, que i) não há associação entre privatização do sistema de previdência e rápido crescimento econômico; ii) o impacto no aumento da poupança agregada é positivo, porém muito limitado na América Latina, nenhuma associação sendo captada no caso dos países do Leste Europeu. No geral, concluem que, nas regiões em análise, o processo de privatização das aposentadorias não produziu impacto estatisticamente significativo nas taxas de crescimento econômico dos países que passaram por reformas, notadamente se comparado à evolução do crescimento nos países que não adotaram tais reformas.

O estímulo às aposentadorias em regime de capitalização, apesar de ser constantemente associado à elevação da poupança privada, não necessariamente vai implicar aumento nessa variável. Por exemplo, caso a previdência complementar seja destinada à aquisição de títulos do governo, essa poupança obrigatória advinda das pensões pode ser amplamente compensada por elevação do endividamento público que financie os custos de transição do regime de repartição para o regime de capitalização (Barr e Dimond, 2008). Além disso, mercados de capital formais podem ou não alocar fundos para investimentos, de forma que o financiamento pode aumentar a poupança, expandir a dívida pública, ou ambos, sem, contudo, estimular o investimento.

Relativamente ao estímulo dos sistemas de capitalização ao crescimento econômico via aumento de poupança, Palley (2006) remonta ao debate entre clássicos e Keynes na década de 1930, destacando se a causalidade ocorre da poupança para o investimento ou do investimento para a poupança. De acordo com o autor, enquanto os clássicos acreditam que a poupança aumenta o investimento pelo pré-financiamento, Keynes (1936) defendia que era o investimento que causava a poupança, não vendo razão para pré-financiamento da acumulação de capital, pois as empresas primeiramente realizam investimentos e, uma vez que esse investimento fosse realizado, ele era contabilizado como poupança. Dessa forma, a poupança não se apresentava como uma restrição à acumulação de capital, mas sim fatores como as baixas taxas de rentabilidade, elevadas taxas de juro reais resultantes de política monetária excessivamente restritiva, dentre outros ${ }^{23}$.

Abordando outra dimensão central das reformas favoráveis à privatização dos regimes previdenciários, Barr e Diamond (2008) afirmam que os regimes de capitalização em nada contribuem para resolver problemas de natureza fiscal (p. 188), muito pelo contrário. A transição de um regime para outro impõe custos elevados aos trabalhadores da ativa, que terão de contribuir para seu fundo individual e também para o pagamento das aposentadorias no fundo público. Agravam o

${ }^{23}$ Como referências para a validade empírica desse resultado, Palley (1998) destaca Ruggles e Ruggles (1992) e Palley (1997). 
problema fiscal na medida em que cabe também ao Estado assumir parte desse custo.

Chamam, ademais, a atenção para o fato de um sistema de capitalização por si só não resolver a questão demográfica. Barr (2004) destaca que apesar de o regime de capitalização ser considerado pela ampla maioria como mais seguro que o regime de repartição, este pode ser visto como um exemplo de falácia da composição, isto é, quando se assume que algo que é verdadeiro em nível individual necessariamente será verdadeiro em nível agregado. Para um indivíduo, a função econômica de um sistema de pensão é o de transferir consumo ao longo do tempo, mas isso não é possível para a sociedade como um todo, pois, de um ponto de vista agregado, a função econômica de um sistema de pensão é dividir o produto total entre trabalhadores e pensionistas. Tendo isso em mente, é possível entender que um sistema de repartição ou de capitalização não possui desempenho muito distinto diante de uma mudança demográfica. Isso porque os aposentados podem consumir somente o que os trabalhadores produzem e não consomem, de forma que os aposentados sempre dependerão das gerações subsequentes para prover o trabalho para produzir os bens de que necessitam para consumir.

Finalmente, há que destacar que "financing a pension system through domestic government bonds is macroeconomically equivalent to a PAYG system" (Barr e Diamond, 2008, p. 96), porque os títulos do governo se tornam uma dívida do Estado e deverão ser pagos por contribuintes, em algum momento no futuro, ao serem resgatados. Da mesma maneira, benefícios a serem honrados pelo regime público de repartição deverão ser pagos, também no futuro, pelos trabalhadores vinculados ao seguro social. O que está em jogo aqui é quem paga. Se os contribuintes do sistema previdenciário público - as novas gerações - ou o conjunto da população, através do sistema tributário. É possível que este seja, inclusive, mais regressivo.

$\mathrm{Na}$ tentativa de sistematizar o que se passou no Brasil, vale recordar que o retorno a um novo ciclo de crescimento econômico na década de 2000 permitiu às receitas da Seguridade Social aumentarem significativamente em valores constantes, passando de R \$ 406,2 bilhões em 2005 para R \$ 744,3 bilhões em 2014 (Lavinas, 2017). Esse pico cede em 2015, já em meio ao primeiro ano de recessão na economia, caindo para $\mathrm{R} \$ 683$ bilhões. As contribuições previdenciárias propriamente ditas mais do que dobram entre 2005 e 2014, e sobem de $\mathrm{R} \$ 203$ bilhões para $\mathrm{R} \$$ 413,03 bilhões, também refluindo em 2015 para R \$352,5 bilhões.

O Gráfico 2 coteja a progressão das receitas do RGPS e o que se passou com o patrimônio dos fundos de capitalização privada abertos. 
Gráfico 2: Brasil, Patrimônio Líquido dos Fundos de Previdência Abertos

e Receitas Previdenciárias, 2005 a 2015 (bilhões de Reais em 2015)

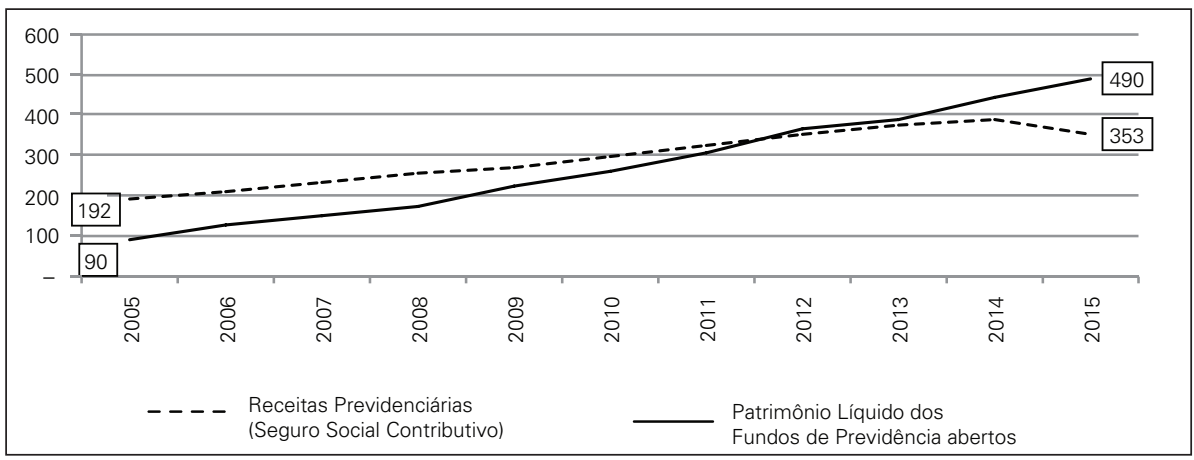

Fonte: ANBIMA e Ministério da Previdência. Valores ajustados pela inflação segundo o índice IPCA para dezembro de 2015.

Constata-se que, a partir de 2012, com a progressiva desaceleração da economia e o recrudescimento das taxas de juros nominais, pela primeira vez o patrimônio líquido da previdência complementar privada aberta ultrapassa a magnitude das contribuições previdenciárias ao RGPS.

É inquestionável, portanto, a atração constante por depósitos em contas individuais, como mecanismo de poupança futura, mesmo em fases de contração da economia. Considerando-se um novo rol de reformas em curso, desta feita mais amplas e profundas, inscritas na PEC 287 - também denominada PEC da Previdência -, cabe indagar em que medida tal tendência viria a acentuar-se, esvaziando as contribuições ao RGPS, provocando, assim, impactos deletérios ao regime público que garante a segurança econômica da grande maioria da população brasileira.

\section{UMA INVESTIGAÇÃO EMPÍRICA ENTRE OS SISTEMAS PÚBLICO E PRIVADO DE PREVIDÊNCIA NO BRASIL}

Esta parte do artigo examina, portanto, como a dinâmica do sistema público impactou na progressão dos regimes de previdência complementar no Brasil e avança algumas hipóteses sobre a natureza e consequências da nova onda de reformas previdenciárias em curso.

Conforme resumiu a terceira seção, o sistema de repartição, consubstanciado na Constituição de 1988, passou por diversas reformas que vêm colocando em xeque a sua sustentabilidade, além de incentivar o desenvolvimento da previdência privada. Destacam-se medidas como o estabelecimento de um teto nominal relativamente baixo para contribuições/benefícios previdenciários e a uniformização do teto entre os dois regimes públicos (RGPS e RPPS). Resta, assim, ao servidor com salário acima do teto do RGPS optar pelo benefício previdenciário complementar, vinculando-se ao fundo de pensão fechado do funcionalismo, votado no segundo 
mandato do presidente Lula, mas efetivamente regulamentado e implementado na gestão Dilma Rousseff. Ambas as medidas são estratégicas para impulsionar a adesão ao regime de capitalização aberto, ainda incipiente e cuja demanda, embora em alta, parece aquém do que esperaria o mercado. Isso se deve certamente à força do INSS ${ }^{24}$ como instituição, que tem o apoio e a confiança da maioria da sociedade brasileira.

Ora, a Proposta de Emenda Constitucional (PEC) 287, ao propor alterações na Constituição Federal com vistas a restringir o direito à Seguridade Social, parece buscar comprometer esse grande diferencial de um regime público. As mudanças pretendidas por essa reforma afetam o acesso à aposentadoria, o valor dos benefícios previdenciários e assistenciais e tendem a rejeitar a possibilidade de acumulação de benefícios.

Os adeptos da reforma defendem, entre outros aspectos:

a. Carência mínima para acesso à aposentadoria: 25 anos de contribuição (em lugar dos atuais 15 anos) e aumento da idade mínima (passando de 55 anos no caso das mulheres e 60 no caso dos homens, para 65 anos para ambos os sexos);

b. 49 anos de contribuição para recebimento da integralidade do benefício, prazo superior àquele vigente nas economias avançadas;

c. Regras únicas para homens e mulheres e para rurais e urbanos, penalizando os grupos mais vulneráveis, com dificuldade de cumprir os requerimentos por tempo de contribuição;

d. Elevação da idade mínima para 70 anos no caso das aposentadorias não contributivas (PBC), atualmente em 65 anos;

e. Redução do valor médio dos benefícios;

f. Desvinculação do piso previdenciário ao salário mínimo.

Como no caso das reformas anteriores, esta, independentemente do que venha a ser aprovado, vai acabar estimulando a expansão dos fundos privados de capitalização, na medida em que propõe medidas que alongam excessivamente o tempo de contribuição e aumentam a idade mínima, com implicações na redução do valor médio do benefício.

Elevar idades, uniformizá-las e aumentar o tempo de contribuição claramente ignoram duas dimensões que podem redefinir o quadro de diminuição do número de contribuintes e a elevação do número de aposentados. São elas: a questão da produtividade e da taxa de fecundidade, ambos fatores cujo dinâmica pode ser alterada através de políticas públicas.

Sobre a primeira, Palley (1998) destaca que a questão da distribuição de

\footnotetext{
${ }^{24}$ Instituto Nacional da Seguridade Social, responsável pela gestão da previdência do RGPS.
} 
renda é central para o problema do crescente envelhecimento populacional, enfatizando a importância da elevação da produtividade e da renda total da economia. No caso da produtividade, coloca o autor, esta é uma variável estratégica para se pensar os sistemas de previdência social, pois como os trabalhadores estão se tornando cada vez mais produtivos devido ao progresso tecnológico, isso implica a redução da carga real de apoio aos aposentados, pois é como se o número "efetivo" de trabalhadores estivesse aumentando via incrementos na produtividade do trabalho. Já no que se refere à renda total, o seu crescimento deve ser suficiente para o provimento de uma renda de substituição à população idosa, como também deve ser repassado aos trabalhadores, pois se o sistema é financiado mediante a cobrança de impostos sobre salários, então os salários também devem crescer para que os recursos destinados ao pagamento de aposentadorias e pensões cresçam com eles. Portanto, conclui o autor, estimular a produtividade e evitar a estagnação salarial é fundamental para o financiamento dos sistemas de pensões público.

É também no mínimo curioso que não se anteveja desde já a necessidade de enfrentar uma taxa de fecundidade não apenas em queda contínua, mas já muito baixa, estimada em 1.7 (IBGE, 2015) por mulher em idade de procriar no Brasil. A França, por exemplo, após implementar políticas natalistas exitosas nos anos 1990, reverteu a tendência e registra hoje a mais elevada taxa de fecundidade de toda a Europa, 2.01, contra 1.58 de média na região (Eurostat, 2014). Na Suécia ocorreu o mesmo: a taxa está em alta (1.88) pelas mesmas razões, pois promoveu-se a conciliação entre altas taxas de emprego feminino e provisão pública de serviços como escola tempo integral e creches que liberassem a força de trabalho das mulheres. Provavelmente o que impede pensar em alternativas desse porte no Brasil, projetadas no futuro, é o mantra da austeridade fiscal, pois estimular a fecundidade significaria relançar investimentos massivos em educação, saúde, não apenas para cobrir o gap existente, mas suprir novas demandas.

A opção pelos sistemas privados parece evidenciada nesse conjunto de desincentivos e limites ao sistema de repartição simples, tornando os fundos privados abertos atrativos, porque menos sujeitos à intervenção do governo. A referida opção é justificada, além da chamada crise do regime público, pelo fomento que poderia conferir, como já exposto, ao crescimento econômico e ao investimento, mediante o estímulo à poupança individual no longo prazo.

Resgatadas essas ideias, é possível levantar duas questões centrais. A primeira delas é qual a relação existente entre os sistemas público e privado, isto é, a fragilidade do sistema público de previdência é condição necessária e suficiente para o desenvolvimento dos sistemas privados, ou, dito de outra forma, o desenho do sistema público de proteção social pode estimular a provisão privada, e como? Já a segunda questão que se coloca é relativa à existência de correlação entre o crescimento dos sistemas de previdência privada e o seu estímulo à poupança, ao investimento e ao mercado de capitais. 
O que segue nesta seção pretende responder a essas questões com uma análise empírica sobre a relação entre variáveis relativas à previdência privada, previdência pública e a possibilidades de financiamento do investimento produtivo e financeiro.

A base de dados utilizada neste estudo é do tipo séries temporais com periodicidade mensal e compreendem os anos de 2002 a 2014, contemplando um total de 154 observações. A Tabela 1 descreve as variáveis utilizadas.

Tabela 1: Variáveis utilizadas no modelo

\begin{tabular}{l|c}
\hline \multicolumn{1}{c|}{ Variável } & Descrição \\
\hline $\begin{array}{l}\text { logdiv } \\
\text { logibovespa } \\
\text { logpppriv }\end{array}$ & Dívida Mobiliária Federal \\
logapesa & Total da Receita da Previdência Complementar \\
logteto & Total da Receita da Aposentadorias e pensões públicas \\
\hline
\end{tabular}

Uma primeira etapa da análise de séries temporais consiste em avaliar se as variáveis seguem um processo estocástico estacionário, o que pode ser feito pela aplicação de testes de raiz unitária ${ }^{25}$.

Uma vez que diversas variáveis foram indicadas como não estacionárias pelos testes de raiz unitária, o próximo passo seria realizar testes de cointegração dos sistemas a serem estimados ${ }^{26}$.

A primeira questão que se busca responder é qual a relação existente entre os sistemas de previdência públicos e privados no Brasil, isto é, se o desenho do sistema público de proteção social pode estimular a provisão privada ou se seu crescimento representa sempre um impasse ao crescimento das aposentadorias complementares. Com base no sistema VAR estimado, a Figura 1 mostra a resposta da variável previdência complementar a um choque positivo na variável previdência pública ${ }^{27}$.

\footnotetext{
${ }^{25}$ Confira Hamilton (1994, cap. 17).

${ }^{26}$ Contudo, com base em Sims, Stock e Watson (1990), optou-se por não os realizar. Segundo esses autores, a finalidade da análise por meio de modelos autorregressivos é determinar as relações existentes entre as variáveis e não os parâmetros estimados, portanto não é relevante se preocupar com a estrutura de cointegração que se estabelece entre as variáveis. Logo, uma estimação de um VAR com todas as variáveis em nível mostra-se consistente. Ressalta-se ainda que, após a estimação do modelo VAR com as variáveis da Tabela 1, foram realizados os testes usuais de robustez (autocorrelação, heterocedasticidade e normalidade dos resíduos) com o propósito de confirmar a confiabilidade dos resultados.

${ }^{27} \mathrm{O}$ Modelo VAR foi estimado com 4 defasagens e seguindo a ordem: previdência complementar, previdência pública, dívida mobiliária, teto do benefício e IBOVESPA. Diversas ordenações foram testadas, mas isso não implicou mudanças significativas nos resultados do modelo.
} 
Figura 1: Resposta da previdência privada a um choque positivo

na previdência pública e no teto da previdência pública

Response to Cholesky One S.D. Innovations \pm 2 S.E.
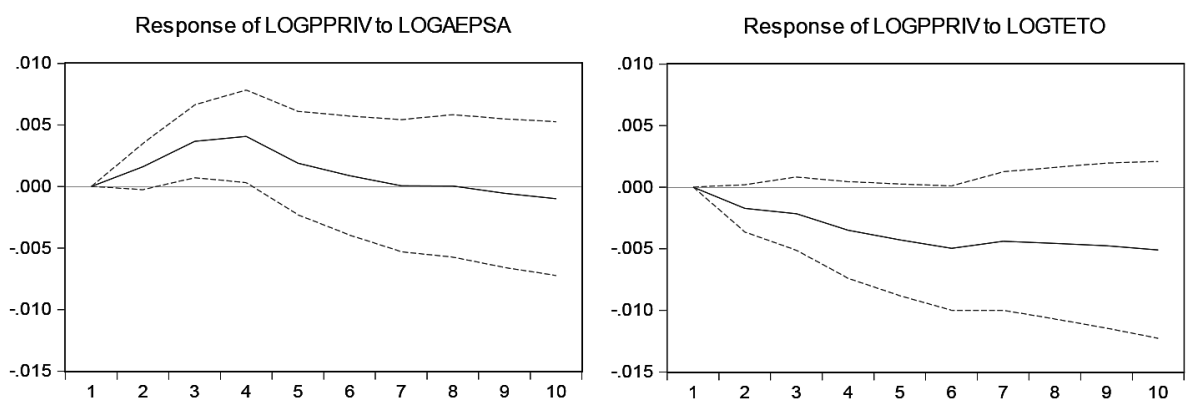

Accumulated Response to Cholesky One S.D. Innovations \pm 2 S.E.

Accumulated Response of LOGPPRIV to LOGAEPSA

Accumulated Response of LOGPPRIV to LOGTETO
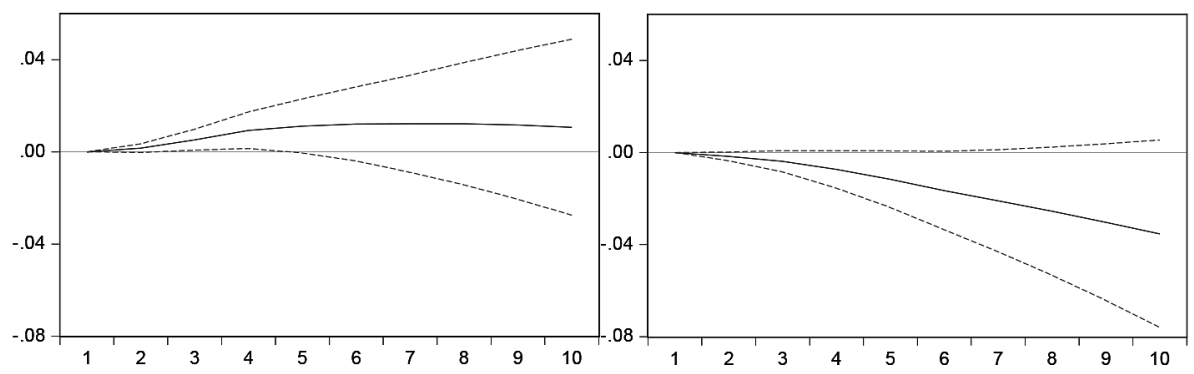

A Figura 1 evidencia que a previdência complementar responde positivamente a um choque que aumenta a previdência pública, sendo o quadrante inferior esquerdo o resultado do choque acumulado e o quadrante superior esquerdo o choque não acumulado. No entanto, a previdência complementar responde negativamente a um choque positivo no teto do benefício previdenciário público, conforme mostram as respostas da previdência privada aos choques acumulados (quadrante inferior direito) e não acumulados (quadrante superior direito) no teto do benefício previdenciário do sistema público.

Dois insights interessantes surgem a partir desse resultado. O primeiro deles é o de que um sistema de previdência público consolidado e sustentável estimula o desenvolvimento de sistemas complementares de capitalização. O segundo é que, haja vista a simetria do choque, a existência de um teto baixo para o benefício previdenciário faz com que os trabalhadores, na busca por assegurar uma renda de substituição mais elevada, compatível com o salário da ativa, voltem-se para o setor financeiro, contribuindo para contas individuais.

No intuito de levantar outras evidências sobre essas relações, a Tabela 2 apresenta o Teste de Causalidade de Granger entre as variáveis previdência pública, previdência complementar e teto do benefício previdenciário público. 
Tabela 2: Teste de Causalidade de Granger (3 defasagens)

\begin{tabular}{lccc}
\hline Null Hypothesis: & Obs & F-Statistic & Prob. \\
\hline DLOGPPRIV não causa, no sentido de Granger, DLOGAEPSA & 150 & 0.99521 & 0.3970 \\
DLOGAEPSA não causa, no sentido de Granger, DLOGPPRIV & 4.07901 & 0.0082 \\
\hline DLOGTETO não causa, no sentido de Granger, DLOGAEPSA & \multirow{2}{*}{150} & 4.10382 & 0.0079 \\
DLOGAEPSA não causa, no sentido de Granger, DLOGTETO & 0.17581 & 0.9126 \\
\hline DLOGTETO não causa, no sentido de Granger, DLOGPPRIV & \multirow{2}{*}{150} & 4.33495 & 0.0059 \\
DLOGPPRIV não causa, no sentido de Granger, DLOGTETO & & 0.41682 & 0.7412 \\
\hline
\end{tabular}

Nota: Como as variáveis do modelo são não estacionárias, os testes de causalidade de Granger foram estimados para as variáveis em taxas de crescimento (diferença de logaritmo).

O teste de causalidade de Granger avalia se uma variável X é importante como previsor de uma variável Y. Mais especificamente, a causalidade de Granger indica se há precedência temporal entre duas variáveis. Observa-se na Tabela 2 que são os movimentos na taxa de crescimento (conceito equivalente a diferença do logaritmo) da variável previdência pública que precedem temporalmente os movimentos na taxa de crescimento da variável previdência privada, indicando que existe precedência temporal da previdência pública sobre a previdência complementar e não o contrário. Portanto, havendo expansão da previdência do regime público, haverá igualmente desenvolvimento do regime privado.

Além disso, a Tabela 2 mostra que a elevação do valor da variável teto do benefício público causa, no sentido de Granger, as variáveis previdência complementar e previdência pública. Isso significa que são os movimentos na variável teto da contribuição que precedem os movimentos nas demais variáveis previdências pública e complementar. Como o teto se relaciona positivamente com a variável previdência pública e negativamente com a variável previdência complementar, é possível afirmar que se houver uma elevação desse teto, haverá expansão da previdência pública, ocorrendo o inverso com a privada.

$\mathrm{Na}$ sequência, as funções impulso-resposta do exercício VAR já discutido anteriormente examinam as influências do crescimento da previdência complementar e as possibilidades de financiamento do investimento produtivo e financeiro. Para isso, a Figura 2 ilustra as respostas da dívida mobiliária federal e do índice IBOVESPA a choques positivos na previdência complementar.

A dívida mobiliária federal se refere aos títulos públicos federais fora do Banco Central do Brasil, compreendendo as Letras do Tesouro Nacional (LTN), Letras Financeiras do Tesouro Nacional (LFT), Bônus do Tesouro Nacional (BTN), Notas do Tesouro Nacional (NTN), dentre outros, assim a resposta positiva da dívida mobiliária federal a um choque positivo na previdência complementar indica que os fundos de previdência complementar estão, em geral, sendo aplicados em títulos da dívida pública, o que na prática implica aumento da dívida. 
Figura 2: Resposta da dívida mobiliária federal e do índice Bovespa a um choque positivo na previdência complementar

Response to Cholesky One S.D. Innovations \pm 2 S.E.

Response of LOGDIV to LOGPPRIV

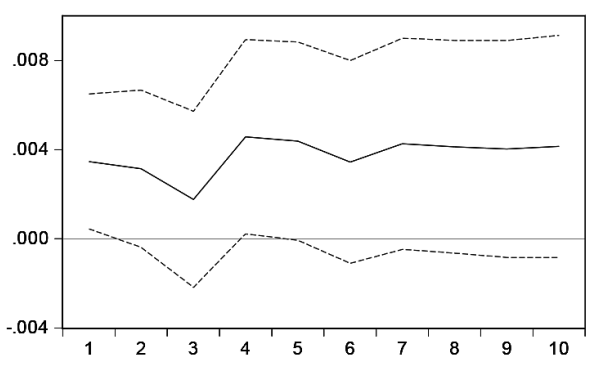

Response of LOGIBOVESPA to LOGPPRIV

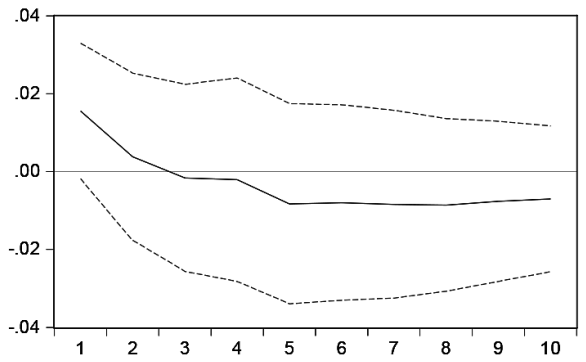

Accumulated Response to Cholesky One S.D. Innovations \pm 2 S.E.

Accumulated Response of LOGDIV to LOGPPRIV

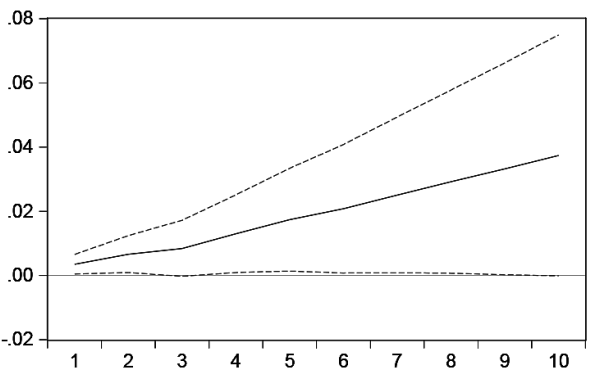

Accumulated Response of LOGIBOVESPA to LOGPPRIV

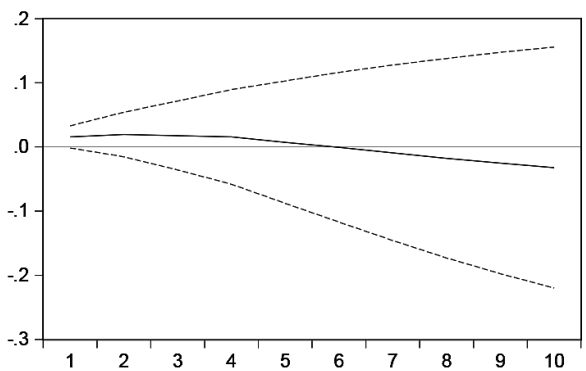

Nesse contexto, no que se refere aos efeitos de uma mudança para sistemas de capitalização via previdência complementar, Barr e Diamond (2008) ressaltam que seus impactos sobre a poupança da economia podem ser muito diversos. Isso porque os recursos dos fundos de pensão podem ser destinados ao financiamento da economia e, dessa forma, aumentar a poupança, mas podem também, como já frisado, ser utilizados para a compra de ativos como títulos públicos, o que não levará ao aumento da poupança total da economia. No segundo caso, se os fundos de pensão são alocados em títulos públicos recém-emitidos pelo governo, o aumento da poupança dos trabalhadores pode ser compensado pelo aumento da necessidade de financiamento do governo, não trazendo os efeitos esperados sobre a poupança agregada da economia.

Sobre a experiência brasileira, Bruno et al. (2011) destacam que a expansão rápida da dívida pública interna, indexada à taxa de juros Selic, representa um dos principais eixos da acumulação rentista-patrimonial no país. Os títulos da dívida pública são, segundo os autores, um mecanismo institucionalizado de extração de recursos públicos, especialmente das classes médias e de baixa renda, que são canalizados para o setor financeiro através do endividamento do Estado. Lavinas (2017) ilustra essa concentração de riqueza com dados referentes aos agentes 
econômicos detentores dos títulos de dívida pública, sendo eles, principalmente, bancos brasileiros e estrangeiros (que mantinham 27,7\% do total dos títulos da dívida pública, em janeiro de 2015), bancos de investimentos (com 20,4\%) e fundos de pensão (com $17,2 \%)$.

Vale ressaltar ainda que, no ano de 2015, segundo dados do Banco Central do Brasil e do Ministério da Previdência e Assistência Social (2016), as despesas com juros consumiram $8,5 \%$ do PIB, enquanto as despesas previdenciárias ${ }^{28}$ foram da ordem de 7,5\% do PIB. Nesse contexto, o debate sobre a reforma da previdência social no Brasil, justificada pela necessidade de controlar os gastos públicos primários do governo em um cenário de desaceleração econômica e elevação da dívida pública, cai em contradição quando se observa que a maior parcela das despesas do governo advém do pagamento dos juros da dívida pública.

Já quanto às respostas do índice de ações IBOVESPA ao crescimento das contas individuais de capitalização destaca-se que o IBOVESPA parece pouco sensível a um choque positivo na previdência complementar. Isso mostra que a justificativa para o incentivo à previdência complementar, tendo em vista sua possibilidade de fomento ao crescimento econômico e ao investimento, mediante o estímulo à poupança individual no longo prazo e ao mercado de capitais, parece não ter fundamento no caso brasileiro.

No intuito de explorar melhor a relação entre previdência complementar e investimento, um modelo VAR é estimado entre as variáveis trimestrais: teto do benefício previdenciário, previdência privada previdência pública e investimento. A função impulso-resposta da interação entre essas variáveis pode ser visualizada na Figura 3.

A Figura 3 ilustra que um choque positivo na previdência complementar tem efeitos negativos sobre a previdência pública e sobre o teto do benefício previdenciário, isto é, o crescimento da previdência complementar está associado à redução da previdência pública e do teto do benefício da previdência social pública sem, contudo, elevar o investimento. Isso porque um choque positivo na previdência complementar não implica elevação na taxa de investimento da economia, como mostra o quadrante inferior da Figura 3. Como discute Barr (2004), o efeito positivo de um sistema de capitalização sobre a poupança, investimento e produto dependente de três relações que não necessariamente se mantêm. A primeira delas é a de que o regime de capitalização leva a uma maior taxa de poupança que o sistema de repartição; a segunda é a de que essa poupança maior será traduzida em maiores e melhores investimentos; e, por fim, a terceira é que esses investimentos levarão a um aumento no produto da economia. Assim, no caso do Brasil, como ilustrado na figura 3 , não foi possível observar estímulos positivos ao investimento advindos da expansão do sistema de previdência complementar.

${ }^{28}$ Total de benefícios previdenciários, para além de aposentadorias e pensões. 
Figura 3: Resposta da variável previdência pública, investimento e teto do benefício previdenciário a choques positivos na previdência privada (choques não acumulados e acumulados)

Response to Cholesky One S.D. Innovations \pm 2 S.E. Response of LOGTETO to LOGPPRIV
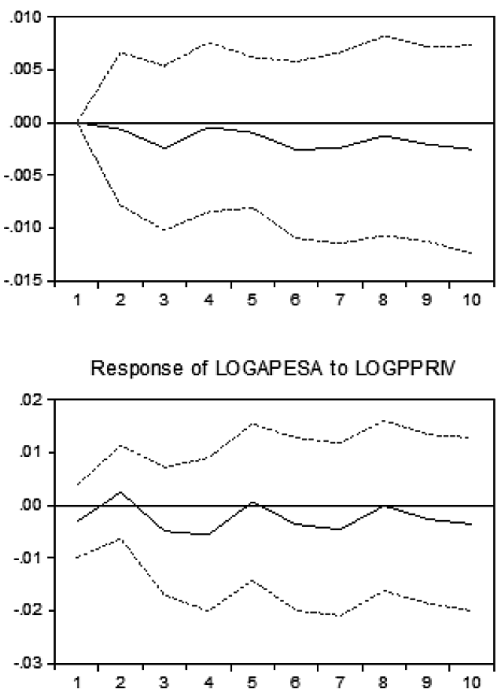

Response of LOGINV to LOGPPRN

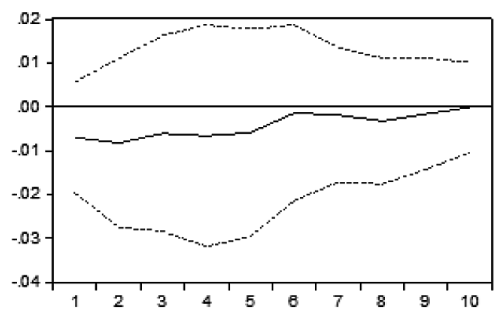

Ac cumulated Response to Cholesky One S.D. Innovations \pm 2 S.E. Accumulated Response of LOGTETO to LOGPPRN

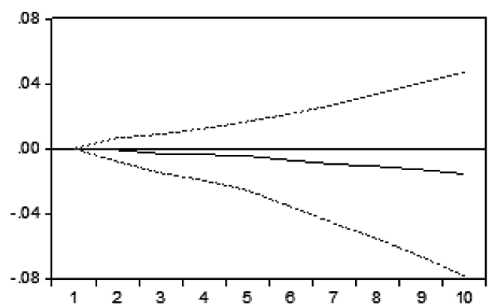

Accumulated Response of LOGAPESA to LOGPPRIV

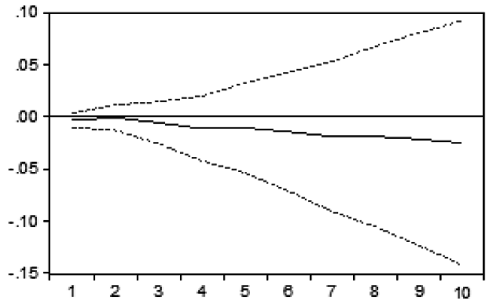

Accumulated Response of LOGINV to LOGPPRIV

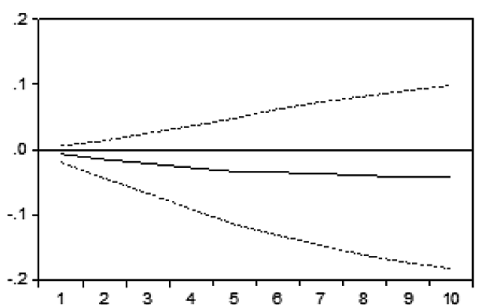

\section{CONSIDERAÇÕES FINAIS E IMPLICAÇÕES NO DESENHO DO REGIME PREVIDENCIÁRIO}

Mudanças no desenho de qualquer regime previdenciário público redefinem o escopo dos benefícios e seus impactos em termos de redistribuição do presente para o futuro, redução das desigualdades e da pobreza entre idosos, bem como da proteção contra determinados riscos ainda na atividade. Este entendimento está consagrado e a reação de apoio ou crítica a cada nova reforma do seguro social reflete uma disputa sobre qual dessas dimensões deve prevalecer, se todas, combinadas, ou apenas uma delas.

Menos frequente, no entanto, são as análises que buscam captar como tais alterações na previdência pública podem estimular ou inibir a expansão dos sistemas de capitalização voluntários. Embora independentes, ambos os regimes podem 
se reforçar ou, ao contrário, atuar num desgaste recíproco. Este artigo buscou evidenciar que relações nutrem o sistema público e o regime de capitalização aberto no caso brasileiro.

A primeira consideração importante, e que vai na direção do que diz a teoria convencional, é que, no Brasil, a consolidação do regime público de repartição contribui para o fortalecimento do sistema complementar privado. Já a recíproca não é verdadeira.

Um segundo aspecto central, embora deliberadamente ausente do debate atual acerca da reforma, trata do teto de contribuição/benefício, comum ao RGPS e ao RPPS. Nosso estudo indica que, para além de uma série de medidas voltadas para elevar a produtividade do trabalho e, com ela, os salários, e reduzir a informalidade, a supressão do teto de contribuição teria efeito dos mais relevantes no desenvolvimento profícuo das aposentadorias públicas. Dessa maneira, a alíquota de contribuição voltaria a incidir sobre a totalidade da remuneração, garantindo mais receitas ao sistema público, se tanto, pois o que se pretende, de fato, é evitar que ele venha a registrar um déficit.

Finalmente, um dos argumentos repisados para justificar incentivos aos regimes complementares de capitalização seria sua primazia em promover o crescimento econômico, através da elevação da poupança privada, ao contrário do regime público, visto apenas como gasto, ignorando-se o caráter multiplicador das aposentadorias igualmente indispensável ao desenvolvimento. Dentre os resultados obtidos destaca-se que, em se tratando de Brasil, a expansão da previdência complementar privada não contribui nem para o aumento do investimento, nem para a ampliação do mercado de capitais. Sendo assim, ela tende muito mais a estimular a concentração de renda mediante, por exemplo, a alocação de recursos em títulos da dívida pública do que promover o estímulo à poupança, investimento e ao crescimento econômico.

Ao sugerir mudanças no sistema de aposentadoria, caso da reforma em curso, devem os formuladores de política considerar questões fundamentais tais como impactos positivos nos mecanismos de financiamento do sistema de bem-estar, sem prejuízos para este ou aquele grupo. Aumentos na produção, reforços ao mercado de capitais e melhorias na eficiência com a qual a poupança é canalizada para o investimento produtivo são fatores que deveriam ser contemplados quando da decisão de alterar os parâmetros da previdência pública. Na prática, claro está que há outros interesses em jogo, que não a real sustentabilidade do regime público.

\section{REFERÊNCIAS BIBLIOGRÁFICAS}

ALTIPARMAKOV N.; NEDELJKOVIC M. (2016) "Does pension privatization increase economic growth? Evidence from Latin America and Eastern Europe”. CESifo - Center for Economic Studies \& Ifo Institute. Working Paper n.6074. September 2016.

BARR, N. (2004), The Economics of the Welfare State, $4^{\text {th }}$ edition, Oxford and New York: Oxford University Press. 
BARR, N.; DIAMOND, P. (2008), Reforming Pensions: Principles and Policy Choices, New York and Oxford: Oxford University Press.

BRUNO, M.; ARAÚJO, E. DIAWARA, H.; REIS, Ana Carolina. S. e RUBENS, M. (2011) "Finance-led growth no Brasil: estatuto teórico, evidências empíricas e consequências macroeconômicas". Revista de Economia Política, vol. 31, n 5 (125), pp. 730-750.

CARVALHO, S. V.; GENTIL, D. L.; PUTY, C. A. C. B.; FRANCÊS, C. R. L.; SILVA, M. S.; SILVA, C. P. A. (2017) "A necessidade do cálculo de dispersão, para projeções sobre o comportamento de sistemas previdenciários”. In PUTY, C.A.C.B.; GENTIL, D. L. (orgs.)- A Previdência Social em 2060: as inconsistências do modelo de projeção atuarial do governo brasileiro. Brasília: ANFIP/ DIEESE; PLATAFORMA POLÍTICA SOCIAL.

EUROSTAT (2014). Social Indicators Data Base. Various years.

GENTIL, D. L.; ARAUJO, E. C.; PUTY, C. A. C. B.; SILVA, C. P. A. (2017) “Uma análise não convencional para o problema da previdência social no Brasil: aspectos teóricos e evidências empíricas". In PUTY, C.A.C.B.; GENTIL, D. L. (orgs.)- A Previdência Social em 2060: as inconsistências do modelo de projeção atuarial do governo brasileiro. Brasília: ANFIP/DIEESE; PLATAFORMA POLÍTICA SOCIAL.

HAMILTON, J.D. (1994). Time Series Analysis. Princeton: Princeton University Press.

IBGE (2015). Sintese de Indicadores Sociais 2015. Rio de Janeiro.

INDEPENDENT EVALUATION GROUP -IEG. (2006) Pension Reform and the Development of Pension Systems - An Evaluation of the World Bank Assistance. Washington D.C.

LAVINAS L. (2017) The Take-over of Social Policy by Financialization. The Brazilian paradox. New York: Palgrave Macmillan. Forthcoming in April 2017.

MESA-LAGO C. (2002). "Myth and reality of pension reform: the Latin American evidence". World Development vol. 30, no. 8, pp. 1309-1321.

PALLEY, Thomas I., (1998) “The economics of social security: An Old Keynesian perspective”, Journal of Post Keynesian Economics, 21 (Fall 1998), No.1.

PALLEY, T.I., (1997) “The Saving - Investment Nexus: Why it Matters and How it Works,"Technical Working Paper T002, AFL-CIO Public Policy Department, Washington D.C..

PUTY, C.A.C.B.; GENTIL, D. L. (orgs.) (2017). "A Previdência Social em 2060: as inconsistências do modelo de projeção atuarial do governo brasileiro”. Brasília: ANFIP/DIEESE; PLATAFORMA POLÍTICA SOCIAL.

PUTY, C. A. C. B.; FRANCÊS, C. R. L.; CARVALHO, S. V.; SILVA, M. S.; SILVA, C. P. A.; (2017) "Quão acuradas são as projeções financeiras e atuariais do Regime Geral da Previdência Social?". In al em 2060: as inconsistências do modelo de projeção atuarial do governo brasileiro. PUTY A Previdência Soci, C.A.C.B.; GENTIL, D. L. (orgs.) Brasília: ANFIP/DIEESE; PLATAFORMA POLÍTICA SOCIAL 2017. 88p.

RUGGLES, N. D.; RUGGLES, R. (1992) "Household and enterprise saving and capital formation in the United States: A market transactions view". Review of Income and Wealth, Series 38, No. 2, June, 119-63.

SIMS, C.; STOCK, J. H.; WATSON, M. W. (2001) "Vector auto-regressions". Journal of Economic Perspectives, v. 15, n. 4, p. 101-115. 